\title{
THERMOCHEMICAL CONVERSION OF BIOMASS
}

\author{
Ralph P. Overend \\ National Renewable Energy Laboratory, Golden, Colorado, USA
}

Keywords: Pyrolysis, Gasification, Syngas, Bio-oil, Thermochemistry, Charcoal, Power generation, Liquid fuels, Methanol, Fischer-Tropsch Liquids, Fast pyrolysis, Counter flow gasifier, Co-current gasifier, Fluidized bed gasifier, Biomass

\section{Contents}

1. Introduction

2. Pyrolysis Fundamentals

2.1. The Chemical Nature of Pyrolysis in the Solid and Gaseous States

2.2. Thermal Aspects of Pyrolysis

3. Pyrolysis Process Technology

3.1. Slow Prolysis

3.2. Fast Pyrolysis

3.2.1. Fast Pyrolysis Process Developments

3.2.2. Bio-oils from Fast Pyrolysis. Properties and Applications

3.2.3 Economics and Environment, Health and Safety (EH\&S) of Bio-oils

4. Gasification Technologies

4.1 Gasification Fundamentals

4.2. Gasifier Systems

4.2.1. The Counter Flow Moving Bed Gasifier (updraft)

4.2.2. Fludized Bed Gasifiers

4.2.3. Entrained Flow Gasifiers

4.2.4. Co-current Moving Bed Gasifiers (downdraft and cross draft units)

4.2.5. Indirect gasifiers

4.2.6 Black Liquor Gasification

4.3 Applications of Gasification

4.3.1 Power Systems

4.4 Liquid Fuels and Chemicals Production

4.4.1 Fischer-Tropsch Production of Hydrocarbon Liquid Fuels

4.4.2. The production of Methanol and Higher Alcohols from Syngas

4.4.3. DiMethyl Ether and Gasolines from Methanol

5. Conclusions

Glossary

Bibliography

Biographical Sketch

\section{Summary}

Thermochemical biomass conversion does include a number of possible roots to produce from the initial biomass feedstock useful fuels and chemicals. The base of thermochemical conversion is the pyrolysis process, which include all chemical changes occurring when heat is applied to a material in the absence of oxygen. The products of biomass pyrolysis 
include water, charcoal (or more correctly a carbonaceous solid), oils or tars, and permanent gases including methane, hydrogen, carbon monoxide, and carbon dioxide. The process be carried out as slow or fast pyrolysis. The progression of traditional slow pyrolysis of a hardwood in a retort that collects the liquids and gases from the process is the following. Starting with $100 \%$ solid material at ambient temperature, by $250^{\circ} \mathrm{C}$ the solid mass is at $88 \%$, less than $10 \%$ liquid, and only a few percent gas. Between $300^{\circ} \mathrm{C}$ and $350^{\circ} \mathrm{C}$ the char mass rapidly decreases to less than $60 \%$, the liquids are $20 \%$ to $30 \%$, and the gases are between $15 \%$ and $25 \%$. The char at this stage contains some amount of both oxygen and hydrogen. Further heating of the char to $750^{\circ} \mathrm{C}$ will decrease the mass of the char, and while its composition moves closer to pure carbon, the yield of gas increases and that of liquids decreases. Typically the slow pyrolysis is conducted for hours to a maximum temperature of $400^{\circ} \mathrm{C}-500^{\circ} \mathrm{C}$. The charcoal yield is $35 \%$ to $40 \%$ by weight. The goal of fast pyrolysis is to produce liquid fuel from lignocellulosic biomass that can substitute for fuel oil in any application. The liquid can also be used to produce a range of specialty and commodity chemicals. The essential features of a fast pyrolysis process are very high heating and heat transfer rates, which often require a finely ground biomass feed. The main product of fast pyrolysis is bio-oil, which is obtained in yields of up to $80 \mathrm{wt} \%$ of dry feed. An extension of pyrolysis is the gasification - a thermal process, which is optimized to give the highest yield of carbon and energy in the gas phase. In most cases the gasification is carried out as a partial oxidation process, in which some air or oxygen is introduced to burn part of the input biomass to provide the heat for pyrolysis and gasification. When oxidant is air, the product contains about 50\% nitrogen. As a result the gas heating value of the fuel gas ranges from $4-6 \mathrm{MJ} \mathrm{Nm}^{-3}$. If pure oxygen is used gasification will produce medium calorific value (MCV) gases in the range of $10-20 \mathrm{MJ} \mathrm{Nm}^{-3}$. Different kinds of gasifiers are used to process the biomass. They differ by arrangement of the feedstock and air flow: the counter flow moving bed gasifier, fluidized bed gasifier, entrained flow gasifier, cocurrent moving bed gasifier. There are also gasifiers where the necessary heat is introduced from an external source (indirect gasifiers). In the last case a MCV gas can be produced. Biomass as a feedstock has a number of qualities, which make its pyrolysis and gasification attractive for various applications. This Article describes the state of the art, the use and draw-backs of those processes.

\section{Introduction}

Pyrolysis is the fundamental chemical reaction process that is the precursor of both the gasification and combustion of solid fuels, and is simply defined as the chemical changes occurring when heat is applied to a material in the absence of oxygen. The products of biomass pyrolysis include water, charcoal (or more correctly a carbonaceous solid), oils or tars, and permanent gases including methane, hydrogen, carbon monoxide, and carbon dioxide. The nature of the changes in pyrolysis depend on the material being pyrolyzed, the final temperature of the pyrolysis process and the rate at which it is heated up. As typical lignocellulosic biomass materials such as wood, straws, and stalks are poor heat conductors, management of the rate of heating requires that the size of the particles being heated be quite small. Otherwise, in massive materials such as logs, the heating rate is very slow, and this determines the yield of pyrolysis products. Depending on the thermal environment and the final temperature, pyrolysis will yield mainly char at low temperatures, less than $450^{\circ} \mathrm{C}$, when the heating rate is quite slow, and mainly gases at high temperatures, greater than $800^{\circ} \mathrm{C}$, with rapid heating rates. At an intermediate temperature 
and under relatively high heating rates, the main product is a liquid bio-oil, a relatively recent discovery, which is just being turned to commercial applications. However, the bulk of commercial and technical pyrolysis processes are applied to the production of charcoal from biomass - a solid biofuel, which is then used as a reducing agent in metallurgy, as activated charcoal in absorption applications after chemical processing, and in domestic cooking in urban areas of the developing world.

Gasification is a complex thermal process that depends on the pyrolysis mechanism to generate gaseous precursors, which in the presence of reactive gases such as oxygen and steam convert the majority of the biomass into a fuel gas. The fuel gas product can in turn be further purified to syngas, which is mainly composed of carbon monoxide and hydrogen, and used to produce chemicals and liquid fuels over catalysts. The majority of fuel gas is used directly to fire processes such as kilns, as fuel in steam boilers, and increasingly as a gaseous fuel in internal combustion engines (ICEs) and gas turbines.

\section{Pyrolysis Fundamentals}

The pyrolysis process consumes energy and, in chemists terms, is described as an endothermic reaction. It is, however, only mildly endothermic; and a factor of much more importance, in terms of energy demand in pyrolysis, is the water content of the starting biomass. The heat of vaporization of pure water is $2.26 \mathrm{~kJ} \mathrm{~g}^{-1}$ at $100^{\circ} \mathrm{C}$, while the chemical energy content of wood is only about $18.6 \mathrm{~kJ} \mathrm{~g}^{-1}$. If there is a high moisture content to begin with, the net energy yield of the pyrolysis process will be very low because the energy necessary for the pyrolysis and gasification processes comes mainly from combustion of one or more of the products of pyrolysis (e.g., char, oil/tar, or combustible gases). Since most biomass is hygroscopic, the removal of water is even more endothermic because of the energy required to overcome the absorption energy. The behavior of solid biomass during heating is a complex interaction between the removal of water and the pyrolysis process. This is further compounded by the occurrence of reactions between the pyrolysis products and the char (see section 4.2.4).

\subsection{The Chemical Nature of Pyrolysis in the Solid and Gaseous States}

Biomass is an organic material that is composed of polymers that have extensive chains of carbon atoms linked into macro-molecules. The polymer backbone chains consist of chemical bonds linking carbon with carbon, or carbon with oxygen, or sometimes other elements such as nitrogen or sulfur. Instead of describing polymers in terms of the atomic structure of the chain, most can be viewed as assemblies of some larger molecular unit. In the case of cellulose, that unit is the glucan moitie [essentially a molecule of glucose with one molecule of water missing $\left.\left(\mathrm{C}_{6} \mathrm{H}_{10} \mathrm{O}_{5}\right)\right]$. For hemicellulose, the unit is often a 5-carbon sugar, called xylose. However, hemicellulose polymers are not linear chains as in the cellulose polymer. Some are branched and other monomer units have side chains, with acetyl groups being very common. The lignin polymers are composed of phenyl propane subunits linked at various points on the monomer through $\mathrm{C}-\mathrm{C}$ and $\mathrm{C}-\mathrm{O}$ bonds. In addition, there are often side chain materials such as methoxy groups. As heat is applied, the chemical bonds become thermally activated and eventually some bonds break. In cellulose the bonds are broken at random locations along the chain composed of thousands of glucan 
moities. The average number of glucan subunits in a chain is described as the degree of polymerization (Dp). Thus, as heat continues to be applied, the polymer goes from a small number of large polymer molecules with a very high Dp, towards many smaller polymers with lower Dp values. As the value of Dp falls to less than 10 or so, the term, polymer, is replaced by the word, oligomer. Depending on the temperature and the applied pressure, eventually the oligomers ranging from $\mathrm{Dp}=8->1$ are volatile (at typical pyrolysis temperatures between $400^{\circ} \mathrm{C}$ and $600^{\circ} \mathrm{C}$ ) and evaporate from the solid mass.

These small fragments are all anhydro sugars; when $\mathrm{Dp}=2$, it is called cellobiosan, and the monomeric version with $\mathrm{Dp}=1$ is called levoglucosan. If these volatile anhydro sugars are not quickly removed from the high temperatures of the pyrolysis, they will also undergo thermal fragmentation, producing highly reactive small intermediates. These in turn, if not removed from the original solid material (as in vacuum pyrolysis), will undergo chemical reactions with the remaining solid materials and may result in the creation of new polymers or accelerate the breakdown of the original chains.

These reactions, unlike the endothermic chain-breaking reactions, can release heat (i.e., are exothermic), and in the pyrolysis of massive materials can result in the propagation of a thermal wave that accelerates the overall pyrolysis reaction. The removal of the products of pyrolysis and quenching them by sweeping them from the pyrolysis reactor into a cold zone (often a condenser), results in their capture for use as chemicals or fuels.

Hemicellulose rapidly loses the side chains, which are often acetyl groups that are condensed as acetic acid. Likewise, lignin, which has methoxy substituents on the majority of the phenylpropane monomer units, leads to the production of methanol. Prior to the advent of petrochemical synthesis, wood pyrolysis was a major source of acetic acid, acetone, and methanol; the latter, as a result, is still known as wood alcohol.

The volatile materials also undergo thermal rearrangements according to the temperature and the duration of exposure to that temperature.

Credit for Figure 1 is due to many researchers in the biomass pyrolysis field, including T.A. Milne and R. Evans, of the National Renewable Energy Laboratory (NREL) USA, and captures the changes taking place in both the solid and the gaseous phases of, for example, hardwood pyrolysis, as the severity of the pyrolysis treatment increases. In reacting chemical systems, the term, severity, is used to capture the idea that both the duration of heating and the final temperature influence the chemical products of pyrolysis.

Very low severity treatments of short duration to a maximum temperature of about $250{ }^{*} \mathrm{C}$ are sometimes called torrefaction, and result in a product that has lost some water and carbon dioxide from pyrolysis while retaining almost all of the heat value. Traditional charcoaling is a medium severity process, while the production of bio-oils is a short duration high severity process, which, if the duration at high temperature is maintained, will go all the way to gas and soot. 


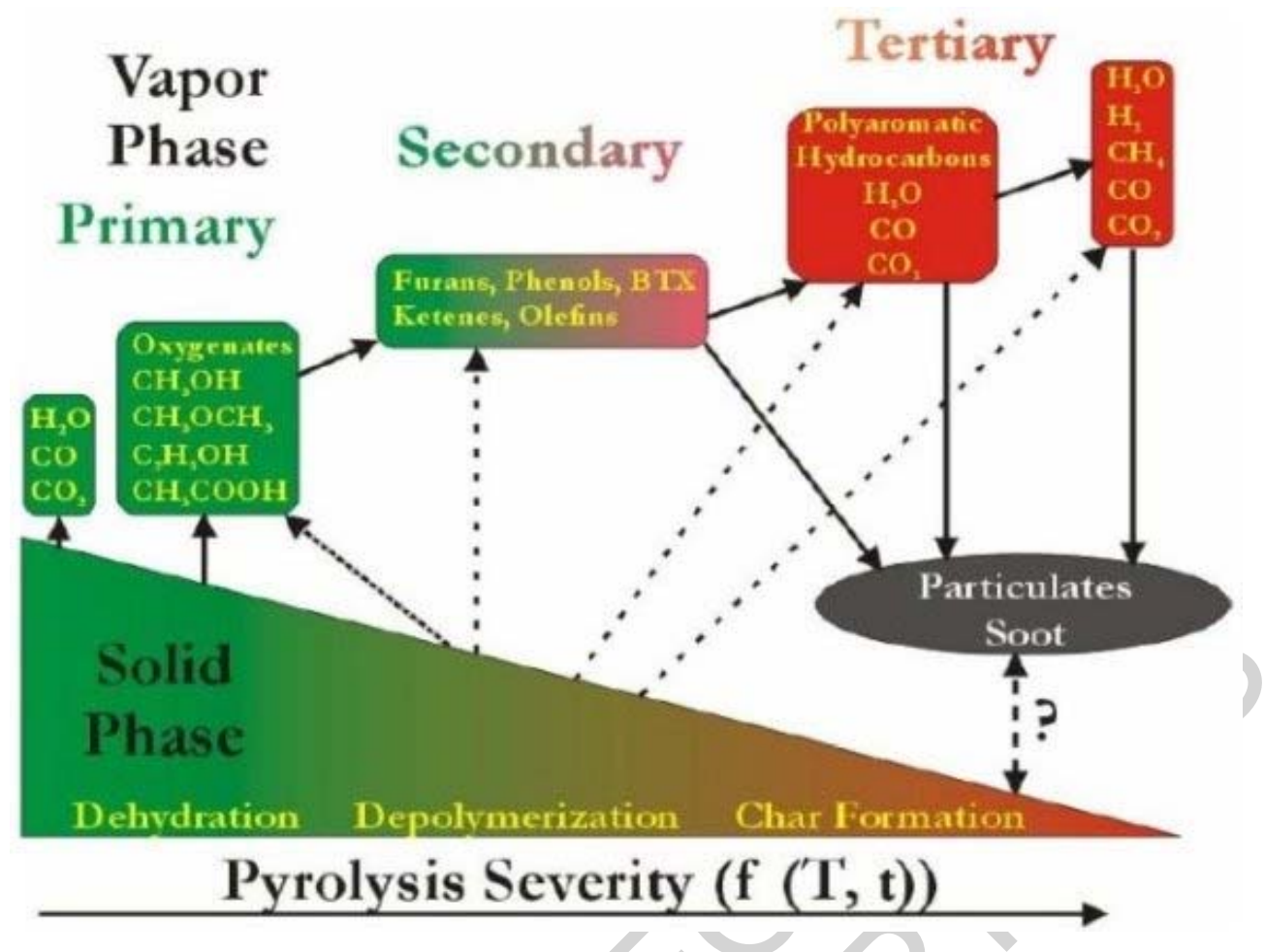

Figure 1 . The primary, secondary and tertiary products of solid biomass as a result of increasing pyrolysis severity

\subsection{Thermal Aspects of Pyrolysis}

Most biomass has a cellular structure with extensive voids, such that while the density of the lignocellulosic cell wall material typically is between $1.5-2 \mathrm{~g} \mathrm{~cm}^{-3}$, the density of wood ranges between 0.2 and $1.3 \mathrm{~g} \mathrm{~cm}^{-3}$ for Balsa wood and Lignum Vitae, respectively. More typical softwoods, such as pine, have values around $0.4 \mathrm{~g} \mathrm{~cm}^{-3}$ and typical hardwoods, such as oak, are about $0.6 \mathrm{~g} \mathrm{~cm}^{-3}$. As a result, the heat transfer characteristics are very poor characterized by the Biot number, a dimensionless ratio of surface convective heat transfer to internal heat conductivity. When the Biot number is very small e.g. $<10^{-3}$ then the material conducts heat rapidly to provide a uniform temperature throughout. However for biomass samples such as wood the Biot number often has values much greater than 0.2, and consequently there are large temperature gradients within the solid wood material. Thus, at high external heat fluxes with large particles of $>2 \mathrm{~cm}$ thick, the surface rapidly reaches the external temperature, while the center of the particle is still cold. For a $1 \mathrm{~cm}^{3}$ cube of wood, a very slow heating rate of $0.01 \mathrm{~K} \mathrm{~min}^{-1}$ (Biot number $\cdot 10^{-5}$ ) would result in an isothermal situation throughout the cube. In this case, the drying of the wood would take place independently of the pyrolysis process. Under the conditions that are often described as fast pyrolysis, the heating rates are on the order of $100 \mathrm{~K} \mathrm{~min}^{-1}$. For the same $1 \mathrm{~cm}^{3}$ cube, the Biot number 0.3 indicates a large thermal gradient, whereas a $1 \mathrm{~mm}^{3}$ cube would more likely to be isothermal with a Biot number 0.003 .

For Biot numbers around unity, the passage of the thermal wave from the outside of the particle to the center takes a relatively long time and is opposed by the diffusion of the 
products of drying (water vapor) and pyrolysis (organic molecules and permanent gases) migrating to the surface. Physically this separates the drying process from the pyrolysis process such that each small volume of wood polymer is totally dry when it pyrolyzes. However, the net chemical result is that the primary products of pyrolysis have close contact with char and can react with the solid char matrix, modifying both it and the composition of the tars and gases. For thermally thick samples in high external heat flux regimes $(\mathrm{Bi}=>10)$, the processes of drying and pyrolysis travel together as a wave through the material. This pyrolysis wave is an exotherm and augments the rate of heat transfer through massive materials.

\section{Pyrolysis Process Technology}

Charcoal has been the major commercial product of biomass pyrolysis for a long time and is the largest single biofuel produced today. Both in historical times, and in developing countries today, relatively simple charcoal kilns have provided charcoal for use as a high quality fuel and as a reducing agent in the winning of ores. The Iron Age was characterized by the use of charcoal, and in Medieval times the increasing industrialization of society resulted first, in the over consumption of wood for charcoal production for use in iron production, and then charcoal was replaced with coke produced from coal. In Brazil charcoal is still produced from wood to produce pig iron, and in Norway wood charcoal is used in metallurgical applications, including the production of silicon for use in solar cells. Current estimates of charcoal production are around $(20 \div 25) 10^{6}$ t. This can be derived from the Food and Agriculture Organization of the United Nations (FAO) forestry data, which shows world charcoal production at $13710^{6} \mathrm{~m}^{3}$ as solid fuelwood equivalent; and using a conversion of $6.0 \mathrm{~m}^{3}$ fuelwood per $1 \mathrm{t}$ of charcoal, the yield is $2310^{6} \mathrm{t}$. Additional charcoal is derived from wood that is not from forests (a weakness in the FAO forestry data base) and non-woody biomass. Globally the primary energy input required to manufacture about $700 \mathrm{PJ}$ of charcoal is approximately $3 \mathrm{EJ}$ of fuelwood.

The off gas and liquids represent as much as $40 \%$ of the original energy of the wood. In simple charcoal making, these are often not utilized, creating pollution of the soil, water and air. In the larger industrial systems, the recovery of byproducts for sale may not be economic compared to fossil-fuel derived products; however, the fuel value of both the gas and the tars (sometimes called pyroligneous liquids) may be utilized in the carbonization process to reduce energy loss, increase efficiency, and eliminate pollution. The destructive distillation of wood in retorts, prior to the coal and petroleum eras, provided a wide range of chemicals, in addition to the valuable charcoal, by condensing the liquids from the pyrolysis process. Before there was extensive chemical synthesis of methanol and acetic acid from fossil fuels, these were both byproducts of charcoal manufacture. Typical mass yields of charcoal and byproduct chemicals for Beech (Fagus sylvatica) are: charcoal $32.5 \%$; gases (with a heating value of $9 \mathrm{MJ} \mathrm{Nm}^{-3}$ ) $¥ 16 \%$; tar $-14 \%$; acetic acid $-7.7 \%$, and methanol - 2.1\% . Charcoal has value not only as fuel and metallurgical reducing agent, but is also the base for the production of special carbons in gas and liquid absorption applications. So-called activated charcoal is charcoal that has been chemically treated at high temperatures to produce an almost pure carbon product with a very high surface area. The absorptive capacity as a result of the large surface areas (e.g., $10^{3} \mathrm{~m}^{2} \mathrm{~g}^{-1}$ ) is extremely large and can trap a wide range of toxic substances and vapors.

\subsection{Slow Prolysis}


Although pyrolysis has been used over a long period of time, the processes taking place during pyrolysis were not understood. This had to await the $20^{\text {th }}$ Century evolution of polymer science and the application of rapid analysis techniques tools. Figure 2 is a summary of the extremes of pyrolysis behavior of lignocellulosic materials. The products of pyrolysis are the char, gases, and liquids, which are composed both of condensed water and the oils or tars from the pyrolysis process.

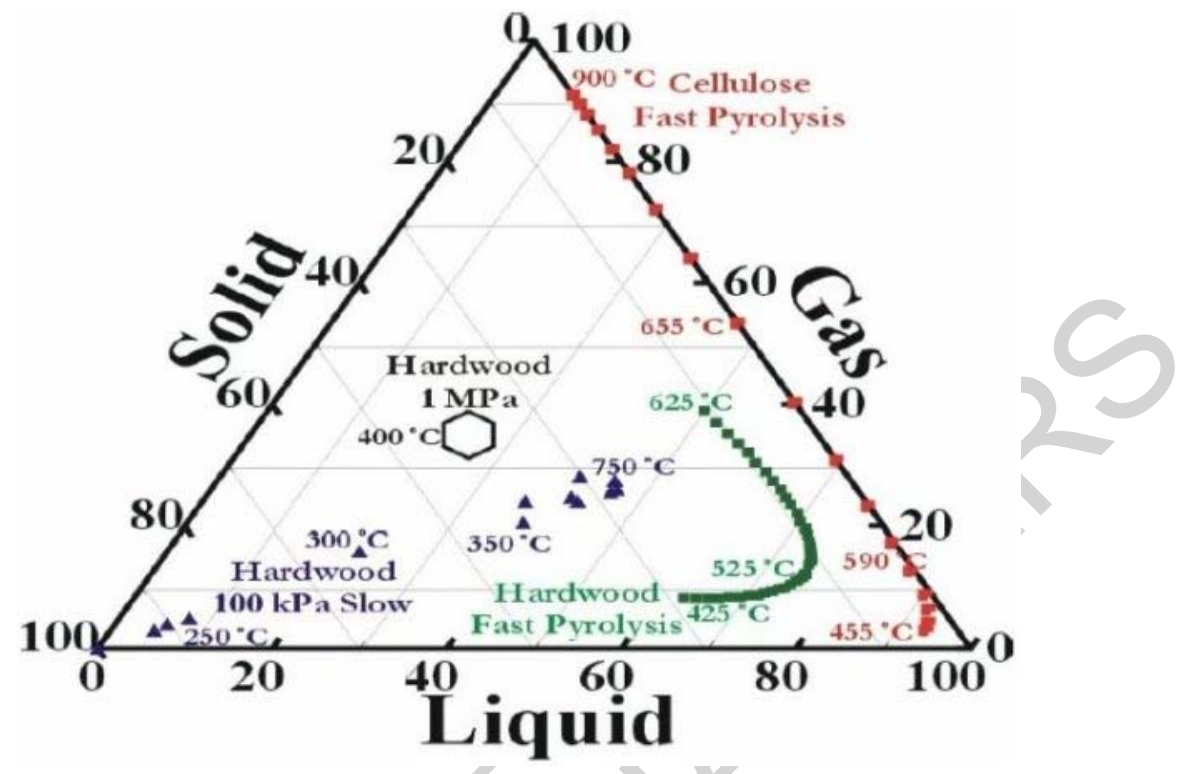

Figure 2. Product gas, liquid and solid ratios as a function of pyrolysis process conditions

The triangles show the progression of traditional slow pyrolysis of a hardwood in a retort that collects the liquids and gases from the process. Starting with $100 \%$ solid material as unconverted hardwood at ambient temperature, by $250^{\circ} \mathrm{C}$ the solid mass is at $88 \%$, less than $10 \%$ liquid, and only a few percent gas. Between $300^{\circ} \mathrm{C}$ and $350^{\circ} \mathrm{C}$, the pyrolysis wave typically starts to move through the mass of the biomass, and the char rapidly decreases to less than $60 \%$ of the mass, the liquids are $20 \%$ to $30 \%$, and the gases are between $15 \%$ and $25 \%$. The char at this stage is not a pure carbon and contains both oxygen and hydrogen. Further heating of the char to $750^{\circ} \mathrm{C}$ will decrease the mass of the char, and while its composition moves closer to pure carbon, the yield of gas increases and that of liquids decreases. Typically the pyrolysis is conducted for hours to a maximum temperature of $400^{\circ} \mathrm{C}-500^{\circ} \mathrm{C}$. The charcoal yield is $35 \%$ to $40 \%$ by weight. The central hexagon shows the theoretical yields of solid char, liquid as water, and gases (mainly methane and carbon dioxide) under the conditions of slow pyrolysis. Until recently it was thought that the theoretical yield was not attainable; however, studies by Professor Antal, at the University of Hawaii, and colleagues from around the world have demonstrated that high pressure carbonization conducted in a retort at $1.0 \mathrm{MPa}$ pressure and a temperature of about $400^{\circ} \mathrm{C}$ will produce almost the theoretical yield; this process is now being commercialized. The high pressure restricts the vaporization and diffusion of the liquid products of pyrolysis out of the body of the pyrolyzing biomass, allowing them to react in the char matrix to produce more char, water and permanent gases. 
The slow pyrolysis process is an example of the pyrolysis wave phenomena in massive biomass, such that the only requirement is for the initiation of the process in which a small proportion of the wood charge is burnt to provide the initial heat in a well insulated reactor. Charcoal manufacture ranges from the artisanal methods of the earth pit or mound, to extremely high technology processes such as the Lambiotte continuous retort. The majority of industrial charcoal is produced in brick kilns, of which the Argentine half-orange and the Brazilian beehive are major examples. Portable steel kilns and permanent concrete kilns with rectangular steel doors are also used; these are sometimes called Missouri kilns. The capacities and throughput of the different systems are shown in Table 1.

\begin{tabular}{|l|l|l|l|l|l|}
\hline \multirow{2}{*}{ Technology } & \multicolumn{2}{|c|}{ Production Cycle } & \multicolumn{3}{c|}{ Performance Data } \\
\cline { 2 - 7 } & $\begin{array}{c}\text { Volume } \\
\left(\mathrm{m}^{3}\right)\end{array}$ & \multicolumn{1}{|c|}{ Days } & $\begin{array}{c}\text { Production } \\
\text { (tonne) }\end{array}$ & $\begin{array}{c}\text { Efficiency tropical } \\
\text { wood/tone of } \\
\text { charcoal }\end{array}$ & $\begin{array}{c}\text { Annual } \\
\text { production } \\
\text { (tonne) }\end{array}$ \\
\hline Earth Pit & 26 & 60 & 6 & 4.5 & 18 \\
\hline $\begin{array}{l}\text { Mound } \\
\text { Cassemance }\end{array}$ & 100 & 24 & 12 & 5.5 & 144 \\
\hline Brick - Argentine & 50 & 14 & 9 & 3.75 & 180 \\
\hline Brick - Brazilian & 45 & 10 & 5 & 2.8 & 175 \\
\hline Missouri Kiln & 180 & 25 & 20 & 3.0 & 240 \\
\hline Lambiotte & 130 & Continuous & & 2.8 & 2500 \\
\hline
\end{tabular}

Table 1. Charcoal production systems

The global average efficiency of charcoal production is about $30 \%$. However, this ranges from $25 \%$ in Africa, which uses mainly artisanal methods, to $48 \%$ in Latin America, which uses industrial kilns. Artisanal methods include the pit and mound methods in which the dry wood to be charcoaled is placed, and then covered with earth to both insulate the reacting wood and to prevent the access of air. One of the oldest illustrations of this technique is by Agricola in his multi-volume work, De Re Metallica, published by Froben and Episopius in Basle in 1556.

\section{TO ACCESS ALL THE 26 PAGES OF THIS CHAPTER, Visit: http://www.eolss.net/Eolss-sampleAllChapter.aspx}

\section{Bibliography}

Bridgwater A. V. (Editor) (2000). Progress in Thermochemical Biomass Conversion. Conference : Progress in Thermochemical Biomass Conversion, Tyrol, Austria, Blackwell Sciences Ltd., Oxford. [Modern understanding of pyrolysis and gasification]

Emrich W. (1985). Handbook of Charcoal Making: the traditional and industrial methods. Dordrecht, D. 


\section{Reidel Publishing Co.}

FAO, Ed. (1983). Simple Technologies for Charcoal Making. FAO Forestry Paper. Rome, Food and Agriculture Organization of the United Nations.

FAO, Ed. (1985). Industrial Charcoal Making. FAO Forestry Paper. Rome, Food and Agriculture Organization of the United Nations.

Probstein, R. F. and R. E. Hicks (1982). Synthetic Fuels. New York, McGraw Hill inc.

Rosillo-Calle, F., et al. (1996). The Charcoal Dilemma: Finding sustainable solutions for Brazilian industry. London, United Kingdom, Intermediate Technology Publications. [Charcoal production and use]

\section{Biographical Sketch}

Ralph P. Overend, NREL Research Fellow, was trained in physical chemistry, and worked in bioenergy and renewable energy since 1973 as a researcher, research manager, and coordinator of research and development in both Canada and the United States. His nearly 20 years with the National Research Council of Canada, was as manager of the Bioenergy program, and advisor to the Department of Energy Mines and Resources on biomass energy. In addition, he served as coordinator of Canadian renewables R\&D for several years. He joined the United States Department of Energy Biomass Power program at the National Renewable Energy Laboratory in 1990, and has worked extensively in the development of long-range plans and strategies for biomass power and biofuels since that time. His major technical activity at the present time is assisting the development of the Vermont Gasification project-a $60 \mathrm{MW}$ thermal indirect gasification system attached to the McNeil station in Burlington, Vermont.

He was the Chairman of the American Chemical Society Cellulose Division 1993-94. He edits the journal, Biomass and Bioenergy, and the biomass section of the Journal, Solar Energy, in addition to being a member of several editorial boards. He has also served as a United Nations, World Bank, and FAO lecturer/advisor in the USSR, China, Pakistan, and Mexico. He recently completed the biomass component of a renewable energy atlas for the Government of the Philippines.

Significant recognitions for outstanding scientific contributions in biomass and bioenergy include: Fellow of the Chemical Institute of Canada, 1990; Johannes Linneborn Prize, 1996; H.M. Hubbard Award, 1997; R\&D 100 Award, 1998; NREL Research Fellow, 2000; the Thomas R. Miles Award, 2001, and the World Renewable Energy Network, Pioneer Award, 2002. 